\title{
A New Methodology for Teaching the Course "Russian as a Foreign Language" in the Digital Environment: Development, Results and Prospects
}

\author{
Elena V. Pinevich ${ }^{1}$, Liudmila V. Panina ${ }^{1 *}$, Olga E. Solianik ${ }^{1}$, and Natalia A. Ionova ${ }^{1}$ \\ ${ }^{1}$ Bauman Moscow State Technical University, 2nd Baumanskaya str., 5/1, 105005, Moscow, Russia
}

\begin{abstract}
The article considers issues covering teaching Russian as a foreign language in a technical university in the preparatory department, using the new online course. The process of production of the online course is revealed. The course structure is described, which includes the following sections: «New Vocabulary», «Reading a Text», «New Grammar», «Listening to Texts and Dialogues», «Complete the Tests», «Interesting Facts about Russia». We mention three possible scenarios of using the online course: 1) an independent distance course (without teachers' participation); 2) a supplementary electronic resource (in traditional full-time studies offline, with teachers' participation); 3) blended learning. The methodology of experimental teaching in the "blended learning system" with the use of the online course "Russian as a Foreign Language: Beginners' Level" is described. Thorough information is given on preparing the experiment, its contingent, conditions, and duration of studies. We mention the peculiarities of studies online versus studies offline. We take into consideration the methods of students' progress control: they are both traditional (written homework was checked by teachers), and automatized (online tests were checked by computer). We analyze the experimental methodology results, and the advantages of both self-studies and classwork. The article concludes with the prospects of the online course "Russian as a Foreign Language" in a technical university and the further development of the following courses: "The Introductory Course of Phonetics and Graphics", "The Scientific Speech Course".
\end{abstract}

\section{Introduction}

Digitalization permeates all areas of human activity, including education. At the present stage, universities focus on training highly qualified specialists with knowledge and skills that meet the requirements of time, production, and science. These requirements lead to changes in the education structure and content. Digital technology usage becomes an essential part of the educational process. The most important task is to create a digital

* Corresponding author: milapanina@bmstu.ru 
educational environment, distance courses, online courses in disciplines, and introduce them into the learning process in such a way that will contribute to the development of communication. At the present stage, much attention is paid to this problem (Romanova, Skorikova, 2018; Kirsanova, Lazarev, 2018; Skorikova, Khromov, Dniprovskaya, 2016; Azimov, 2016; Karpov, 2015, 2017; Lederman, 2013; Armstrong, 2000) [1,2,3,4,5,6,7,8].

Responding to the trends and requirements of the new time, universities are introducing experimental programmes on the use of digital technologies in teaching students various specialties. The works of N.Sh. Kozlov, T.E. Lebedeva, Yu.I. Dimitrienko, and others $[9,10,11]$ propose innovations in solving these problems. Since 2018, Bauman Moscow State Technical University (BMSTU) actively implements the project of creating online courses in various disciplines and including them in the educational programme. We should note, that computerization has affected not only technical subjects (in which humanmachine interaction is expected), but also humanitarian areas (which are based on interhuman interaction). Initially, switching to online training seemed questionable, as far as it concerned teaching foreign languages (the subjects that are surely considered to be "pure" classroom studies). It is obvious that education in this sphere is based on direct contact between the student and the teacher, as well as other students in the group, and is particularly built on speech communication. However, the Russian Language Department accepted the challenge and became the first department in the BMSTU Linguistics Faculty, who boldly started the experiment.

\section{Russian Language Online Course}

\subsection{Online Course Development}

When creating an electronic educational environment, a number of questions inevitably arise: Is it possible to improve the educational process using the computer programmes? Is it possible to remove the teacher from the educational process? What is the teacher's role in the new digital world? What skills do the teacher of the future need to develop? How does the study time and the student's learning activity change? What new systems and mechanisms for assessing knowledge must be created?

The future creators of the online Russian language course for foreign students had to answer these questions and overcome some difficulties (both expected and unforeseen). We decided to start the experiment with the basics (which is logical) - with working on a course of Russian as a Foreign Language (RFL) for Beginners (Level A1). The main difficulty was the lack of experience in creating an online course. However, the authors had already got the experience in remote teaching of RFL to Chinese students during several years, in creating electronic textbooks, as well as in using PowerPoint presentations and other electronic materials in the classroom. When preparing the new online course, we also created presentations, recorded video tutorials on their basis, collected an audio materials database, and made tasks for median and control testing. The result of this creative work was the appearance of the online course "Russian as a Foreign Language (A1)" by the beginning of the new academic year 2018-2019. The course is placed on the platform "Open BMSTU", it is available to all BMSTU students who have an account, and in the future will be available to students of other technical universities.

\subsection{Online Course Description}

The course is based on the new textbook "Sputnik (Satellite)", written by a group of authors of the BMSTU Russian Language Department [12]. The course is specially designed for 
technical university students of preparatory departments, which is reflected in the choice of topics and vocabulary (in particular, educational, student-household, scientific and technical spheres). The textbook authors sought to select only the most important and relevant material, excluding unnecessary, non-essential, in order to help students get used to the university and student life more quickly, as well as to prepare them for further studies in bachelor's and master's degrees at a Russian university, getting education in Russian, and to successfully master knowledge in technical specialties.

The online course is meant for 10 weeks of study and is divided into three grammatical parts: 1. Nouns, adjectives, pronouns. 2. Case system of nouns. Verbs. 3. Compound sentences.

The course (following the tutorial "Sputnik") comprises 25 lessons. Each lesson introduces new grammar and a new vocabulary topic, which are related as follows.

Table 1. Vocabulary and grammar topics of the online course.

\begin{tabular}{|c|c|c|}
\hline Lesson & Vocabulary topic & Grammar topic \\
\hline Lesson 1. & Acquaintance & Gender of nouns \\
\hline Lesson 2. & University & Animate-inanimate nouns \\
\hline Lesson 3. & My home & Adjectives \\
\hline Lesson 4. & My family & Personal pronouns \\
\hline Lesson 5. & My dormitory & Possessive pronouns \\
\hline Lesson 6. & $\begin{array}{l}\text { At the buffet, in the } \\
\text { canteen, in the cafe }\end{array}$ & Demonstrative pronouns \\
\hline Lesson 7. & At the shop & Plural of nouns and adjectives \\
\hline Lesson 8. & A study day & Imperative \\
\hline Lesson 9. & At the lesson & Verbs of I conjugation (Present tense) \\
\hline Lesson 10. & Free time & Verbs of II conjugation (Present tense) \\
\hline Lesson 11. & Talking about yourself & Past tense \\
\hline Lesson 12. & On an excursion & Prepositional case \\
\hline Lesson 13. & Vacations & Accusative case \\
\hline Lesson 14. & Trips & Verbs of movement "идти / ехать" \\
\hline Lesson 15. & Travelling & Verbs of movement "ходить / ездить" \\
\hline Lesson 16. & Daily routine & Aspects of verbs \\
\hline Lesson 17. & Plans, dreams & Future tense \\
\hline Lesson 18. & Gifts & Dative case \\
\hline Lesson 19. & My room & Genitive case \\
\hline Lesson 20. & At the museum & $\begin{array}{c}\text { Verbs of movement "пойти / прийти, } \\
\text { nоехать / приехать"” }\end{array}$ \\
\hline Lesson 21. & Hobbies & Instrumental case \\
\hline Lesson 22. & In the city & $\begin{array}{l}\text { Compound sentence with the words "потому } \\
\text { что/поэтому" }\end{array}$ \\
\hline Lesson 23. & Profession & $\begin{array}{l}\text { Compound sentence with the words " } ч m o / \\
\text { чтобьl" }\end{array}$ \\
\hline Lesson 24. & Time & Compound sentence with the word "когда" \\
\hline Lesson 25. & My schedule & $\begin{array}{c}\text { Compound sentence: simultaneous and } \\
\text { sequent actions }\end{array}$ \\
\hline
\end{tabular}

The online lessons have a certain structure. For each lesson we recorded video tutorials. They were divided into fragments from 5 to 10 minutes. These fragments correspond to the following sections: 1) new vocabulary introduction, reading improvement, new words 
pronunciation and memorization (section "New words"), 2) texts with pre-text and post-text tasks for checking comprehension of the content of the written text (section "Read the Text"), 3) introduction and explanation of new grammatical topics, assignments for practicing new grammar skills (section "New Grammar»), 4) communication tasks for developing speaking skills and acquiring new vocabulary and grammatical forms (section "Let's talk!"), 5) listening with the follow-up questions on understanding dialogue speech (section "Listen to the Dialogues"), 6) listening comprehension of the text with the followup tasks on understanding monologue speech (section "Listen to the Text"). The variety of sections allows students to fully master the vocabulary and grammar material and get the skills of reading, listening and speaking.

We should mention that the video lessons were recorded by several speakers, which helps listeners to be able to percept Russian-sounding speech from different people, produced in different manners. It is also important that during viewing the video lessons, students can see the teacher's face in the lower right corner of the screen, watch the teacher speaking and can relate the visible part of his/her articulation (the mouth opening size, the lips and tongue movement) to the pronunciation of sounds; and later, students can reproduce the same articulation movements when pronouncing Russian sounds on their own.

The video tutorials were recorded on the base of presentations (created in PowerPoint). On one hand, the material is presented in a clear and structured form - in tables and schemes. On the other hand, the slides are bright and illustrative, that evokes an emotional response from students. All this contributes to the active perception and memorization of new material. Listeners of the online course also have access to the presentations, that were used in videos, and can view them separately from the video lessons. We place them in the "Additional Materials" section.

The important role in the online course is given to testing. The examinations in Russian as a foreign language taken by Preparatory Department students in the end of an academic year are conducted in a test form [13]. Thus, the test tasks at the level A1 not only perform the controlling function, but also serve as a training base for further preparation to the final examination. Our experience of implementing the online course in training has shown that the number of test tasks in each section must be over 100, in order to allow students to repass the lesson test and to re-check the knowledge of new grammar and lexical units in case of failure or misunderstanding.

Each online lesson provides students with test tasks that are supplied with automatic answer verification, and the results are displayed immediately. The types of the online tests are various. Here are some examples of tasks: 1) "Listen to the dialogue and answer the questions!" (listening task), 2) "Read the text and answer the questions!"(reading task), 3) "Choose the correct answer!"(vocabulary and grammar tasks), 4) "Match the words and the pictures!" (vocabulary task), etc. Thus, students receive instant feedback and find out whether there is a need to review the new material.

Test tasks of the lesson are divided into median tests (for practice and self-control during the lesson) and control tests (at the end of the lesson). Besides in- and after-lesson tests, the system offers tasks for midterm control (intermediate tests) and final control (final test), which completes the Level A1 course.

In addition to videos, tests, and presentations, each online lesson is provided with vocabulary page, which summarizes the new words of the lesson and gives their analogues in English. Also, at the end of each lesson, there are homework assignments that are presented in the traditional form (like tasks in a textbook) and are intended for writing in a notebook. 
Currently, we have added dictations in the course. Students now get the opportunity to check how well they have mastered the vocabulary of the lesson. After listening to a word, the student enters it in a special "window" using the keyboard, and then the correct answer appears.

Both the student and the teacher can see the progress in the section "Progress", which shows the results of training in the form of a diagram; each completed task has its score. Thus, the teacher can track the student's activity and progress remotely.

At the end of the course, students get a volume of knowledge corresponding to the Level A1 of the Russian language, and acquire speech activity skills - reading, listening, writing. However, it is important to emphasize that sufficient development of speaking skills, skills of participation in unprepared dialogues remains the prerogative of classroom lessons. The development of these skills is possible only with direct, live communication and with constant guidance from the teacher. At the moment, the solution of this problem only with the help of computer programmes seems to us unrealizable (at least in the short term).

\subsection{Online Course Using Options}

How should we fulfil the task (assigned by the BMSTU Rector) of implementing online courses in university educational programmes? We suggest three possible scenarios of using our electronic product.

1) as an independent distance course (without the participation of the teacher).

2) as a supplementary electronic resource for the main full-time training.

3 ) in blended learning, where the ratio of classroom time with the teacher and self-study of students in the online course is distributed evenly $(50 \%-50 \%)$.

Let us take a closer look at these options.

As for the first option, it has yet to be tested. The online course "Russian as a foreign language (level A1)", prepared at BMSTU, may become a massive open course that people from different countries, cities and universities can remotely take, and also receive a certificate upon its successful graduation. At this stage, we are preparing to publish the course on a publicly available Russian platform. The work of Pinevich E.V. [14] considers the questions of choosing a platform and placing online courses on it. At the same time this course is being tested with students from Syria who have not yet started their studies at the university because of various circumstances but have the opportunity to start learning Russian in their country due to the availability of the Internet. But a massive open online course involves a significant number of elements and tasks since it is not designed for feedback [15]. In this regard, it requires more thorough preparation and production, creating new tasks focused primarily on writing, speaking and reading skills development.

The second option involves using the online course as additional material for traditional full-time training. This experience is obtained by teachers and students who are engaged in the Preparatory Faculty of BMSTU in the autumn semester of the academic year 20192020. Teachers use the new textbook "Sputnik" as a basic teaching tool in their lessons, which corresponds to the online course. What kind of support does the online course provide in the learning process? A student who missed a class can apply to the online course and learn a new topic on their own. A student with low academic performance who has not mastered enough material can get a recommendation from the teacher to view a video tutorial on a particular topic. Students who are preparing for a test or an exam have the opportunity to review the material using the online course, and this, in our opinion, is much more exciting and effective than the ordinary task "Learn by heart!". Papers by N.A. Ionova and O.E. Solyanik $[16,17]$ are devoted to the experience of the combined work on the textbook "Sputnik" and in the online course. 
The third option of using the online course in the educational process is "blended learning". This type of training is considered to be the most efficient, it becomes more and more popular all over the world. It involves a combination of an independent distance learning of the subject by students, and regular meetings with the teacher [18, 19, 20]. This option assumes that the study time is divided into two equal parts: online activities take as much time as classroom work. We carried out the experiment on the blended learning in BMSTU in the spring semester of 2019. Below we describe this experiment in more detail.

\section{Blended Learning Experiment}

\subsection{Preparing for the Experiment}

The organizers of the experiment tried to implement electronic educational tools in the learning process as much as possible. Thus, the special feature of blended learning in BMSTU was teaching classes in classrooms, technically equipped according to the requirements: the classes had individual computers for students, with connected sound and Internet access; a computer for the teacher, connected to sound speakers and to a largescreen projector or a whiteboard next to the teacher's desk. All this equipment allowed teachers to conduct computer testing of students (based on the online course tests) under personal control and actively use both visual tools (presentations with texts and tasks for training) and audio materials (training dialogues recordings) in the classroom. Evidently, before the experiment began, the participants did a huge amount of work to prepare new elearning materials. Those presentations, that were intended to be used during the classroom work, corresponded to the topic, but did not copy the presentations from the online course. Thus, all the practical classroom tasks offered to students were new and differed from the online tasks.

The experiment involved three groups of 9-11 people (30 students in total) studying at the BMSTU Preparatory Faculty - students from Syria, Vietnam, and China. The groups were selected for a reason: they were "late arrival" groups, meaning they started learning the Russian language later than other students of the Preparatory Faculty, and the experiment was meant to help students pass the RFL shorter course in order to take the final exam in Russian at the same time as the entire preparatory course, in the summer. Before starting the experiment, students had to get individual passwords to log in to the University Internet access and the platform "Open BMSTU", and sign up for the Russian online course.

\subsection{Course Structure}

Duration. Following the set structure of the 10-week online course, we also distributed classroom sessions over 10 weeks (see table 2). Classes with students were held one or two times a week. During classes, instead of a traditional textbook, we used electronic tools presentations projected on a large screen, and many audio recordings turned on by the teacher for listening through speakers. We should note that such an active use of technology and modern learning tools in the classroom was extremely motivating for students. 
Table 2. Weekly calendar plan.

\begin{tabular}{|c|c|c|c|}
\hline Week \# & Content of the lesson & $\begin{array}{c}\text { Number of } \\
\text { classroom } \\
\text { hours }\end{array}$ & Dates \\
\hline 1 & Lessons 1, 2, 3 & 6 & $11.02-17.02$ \\
\hline 2 & Lessons 4, 5 & 6 & $18.02-24.02$ \\
\hline 3 & $\begin{array}{c}\text { Lessons 6, 7. } \\
\text { Intermediate test 1 }\end{array}$ & 6 & $25.02-03.03$ \\
\hline 4 & Lessons 8, 9, 10 & 6 & $04.03-10.03$ \\
\hline 5 & Lessons 11, 12, 13 & 6 & $11.03-17.03$ \\
\hline 6 & Lessons 14,15, 16 & 6 & $25.03-31.03$ \\
\hline 7 & Lessons 17, 18, 19, & 6 & $01.03-07.04$ \\
\hline 8 & $\begin{array}{c}\text { Lessons 20, 21. } \\
\text { Intermediate test 2 }\end{array}$ & 6 & $15.04-21.04$ \\
\hline 9 & Lessons 22, 23, 24 & 4 & $22.04-28.04$ \\
\hline 10 & $\begin{array}{c}\text { Lesson 25. } \\
\text { Intermediate test 3 }\end{array}$ & & \\
\hline 11 & Final test & 64.04 \\
\hline
\end{tabular}

The structure of the lesson (classroom session). Most part of the lesson was devoted to the teacher's joint work with students. The lesson was conducted according to the set structure: introduction of the lesson topic, introduction to new vocabulary, grammar explanation, reading texts, listening to dialogues, completing tasks (answering questions) on texts and dialogues, practicing lexical and grammatical materials in tasks of various types, automating speech skills and fixing grammar in dialogues on a given topic and in role-play dialogues.

Part of the lesson was devoted to students' individual work - completing tasks in a test form on a computer. We used tasks from a corresponding lesson in the online course. To do this, students had to log in with an individual password to the "Open BMSTU" website, select the Russian online course (among other university online courses), find the necessary lesson, and start completing tasks. The programme checked the tasks automatically, but the teacher also monitored the completion of tasks, and could see the difficulties that students met. Also, students had the opportunity to ask the teacher questions about the mistakes they made in the tests and to get an explanation. This communication during testing prompted the teachers to what they should pay special attention, what material they should review and practice more thoroughly.

Homework. At the end of the lesson, students received writing home task which ought to be completed in a notebook and then to be checked by the teacher. They were also given the main task - to view the videos of online lessons on the topics covered that day in the class. We assumed that such a format of training in an online course (the self-study of an online lesson follows the classroom session) contributes to the review and consolidation of the studied material. Access to online lessons was opened for students gradually, sequentially, and weekly. However, some online lessons were studied by students on their own before live classes with the teacher. This format turned out to be also acceptable. In this case, in the class the teacher explained the difficulties encountered by students, as well as answered the questions raised, and the material was reviewed. 
Progress monitoring. During the course, students passed three intermediate tests (after completing each unit). At the end of the course, we conducted the final test on the knowledge obtained throughout the course. All control measures were aimed at checking all types of speech activity and included five types of tasks: 1) vocabulary and grammatical test, 2) listening to dialogues and texts (with tasks in a test form), 3) reading (a text followed by questions and variants of answers), 4) writing (an essay of a certain length, on a given topic), 5) speaking (participating in a dialogue and answering questions). We automated the first three types of tasks and carried out them online at the computer. The last two types required the teacher's presence and supervision, and therefore we conducted them during classroom sessions.

\subsection{Experiment Results}

First of all, the experiment allowed us to conduct the first trial of the new online course and get direct feedback from the participants. Some inaccuracies and typos were found, as well as failures in the programme (in particular, in testing). Data about errors were carefully collected by both teachers and students, and then sent to programmers to be corrected. Moreover, we made conclusions about supplements and improvements, that could be added to the course.

Students enthusiastically took part in the experiment. At the end of the course, students showed high results in mastering the course programme, as it is evidenced by the scores they received for Intermediate and Final testing (see table 3).

Table 3. Prep.Dep.-164T group, first intermediate test results.

\begin{tabular}{|c|c|c|c|c|c|c|c|}
\hline Students & $\begin{array}{c}\text { Vocabulary/ } \\
\text { Grammar }\end{array}$ & Reading & \multicolumn{2}{|c|}{$\begin{array}{c}\text { Speaking } \\
\text { (questions/ } \\
\text { dialogues) }\end{array}$} & Listening & Writing & $\begin{array}{c}\text { Final score } \\
\text { (5- excellent, } \\
\text { 4- good) }\end{array}$ \\
\hline № 1. & 5 & 5 & 4,5 & 5 & 5 & 5 & 5 \\
\hline № 2. & 5 & 5 & 5 & 5 & 5 & - & 5 \\
\hline № 3. & 5 & 5 & 4 & 4 & 4,5 & 5 & 4,5 \\
\hline № 4. & 5 & 5 & 5 & 5 & 5 & - & 5 \\
\hline № 5. & 5 & 5 & 5 & 5 & 5 & 4 & 5 \\
\hline № 6. & 5 & 5 & 5 & 5 & 5 & 5 & 5 \\
\hline № 7. & 5 & $5-$ & 5 & 5 & 5 & 5 & 5 \\
\hline № 8. & 5 & 5 & 5 & 5 & 5 & 5 & 5 \\
\hline № 9. & 5 & 5 & 4 & 5 & 5 & 5 & 4,5 \\
\hline № 10. & 5 & 5 & 5 & 5 & - & - & 5 \\
\hline № 11. & 5 & 5 & 4 & 4,5 & 5 & 5 & 4,5 \\
\hline
\end{tabular}

During the classes, the teachers could observe the students' positive reaction and excitement about the way the educational material was introduced (in PowerPoint presentations). As for the teachers themselves (the presentations authors), they were also excited, feeling new opportunities to reveal their creative potential.

At the end of the experiment, we surveyed the students. They left positive comments on the online course, describing it as helpful and convenient. They expressed their gratitude both to the course creators, and the teachers who conducted the lessons. The students wished for the course authors to successfully overcome difficulties and to continue the work on creating online courses for teaching Russian at the upper levels.

The blended learning methodology is based on the combination of classroom activities and online self-study. Thus, the advantages of these two types of work are combined, and this becomes the main privilege of the new type of training.

The advantages of students' individual work online are the following: 
- access from any mobile device;

- the opportunity to enter the course at any time convenient for the student;

- the possibility of learning a lesson in parts;

- the chance to repeat the material, to return to the previous lessons if necessary;

- structured, easy to perceive, visually rich presentation of the material;

- automated knowledge control.

The advantages of classroom work are the following:

- oral speech practice;

- written speech practice;

- the opportunity to get the teacher's advice on emerging issues related to the study of new grammar and vocabulary;

- receiving error correction (in pronunciation, intonation, grammatical forms, word usage, syntactic structures, and communicative language) from the teacher.

Thus, we may conclude that the experiment was successful. The new method of teaching Russian as a foreign language in a digital environment helps to improve the educational process quality, opens new opportunities for teachers, and increases the efficiency of getting the necessary skills and knowledge by students.

\section{Online Course Prospects for the Development}

At the present moment, we continue working on the improvement and development of the online course. We are developing our course in several areas simultaneously. One of these areas is automated testing. Most of the tests that we use throughout the course are of the type "choose the correct answer from the list of given variants". Evidently, there is a need in more variety of tasks, as well as in more complicated tasks. We are also looking for new ways for students to enter their answers to questions of the test. For example, typing (rather than clicking) is highly desirable in the process of learning. We have to admit that we face difficulties in inventing such computer tests that would fully and adequately evaluate the knowledge and skills acquired by students.

The next area in which we expand our online course is adding extra information that may be interesting and/or useful for students. For instance, we supply the course with a series of materials of a country-specific nature (posted in the section "Interesting facts about Russia"). It tells about Russian towns and cities, Moscow landmarks, famous Russian scientists, holidays and traditions in Russia, etc. This information is given in presentations, each of them contains a text on a certain topic, supported with photos, pictures, and followup tasks checking text comprehension and reviewing grammatical forms and syntactic structures. Each topic is related to one of the twenty-five lessons of the online course: it is based on the grammar theme of the lesson and uses the vocabulary relevant at this step of learning Russian (which is vital for the level "Beginner"). Therefore, these presentations will also provide students with additional practice in reading and grammar. The information chosen for this country studies course takes into account the personality and interests of the listener for whom the online lessons are intended - he is a future engineer, a student of a technical university who lives in Moscow, in his free time he visits museums and parks, and on vacation he is eager to travel around Russia. The course aims to introduce readers to Russian cultural values and scientific achievements, broaden their horizons, develop curiosity and instill a love of the Russian language and Russia.

Furthermore, we realized that there is a need for an introductory course of Phonetics and Graphics. This section is supposed to precede and supplement the online course, introducing students to the Russian alphabet, pronunciation, etc. It is worth noting that even at the stage of presentation of the Russian letters, the course creators try to follow the main guideline (the course is intended for students of technical specialties) and select the 
engineering vocabulary. In the course we set both graphical and phonetic goals. In the graphical part we represent printing and handwriting fonts, teach reading and writing in Russian. The phonetic part includes working on the correct pronunciation of Russian sounds; developing listening skills, i.e. distinguishing sounds by ear; acquiring the accentological model of the Russian word; learning the basic rules of phonetic reading, such as reducing and changing the quality of vowels in an unaccented position, devoicing consonants in the end of a word, etc.; initial mastering of primary Russian intonation structures.

Thus, the online course of Russian for Beginners is extensively being increased by additional tests, country-study texts and detailed phonetic section. Besides that, we are working on continuation of the course. An online course of Scientific Speech Style for future engineers is being created. This course is intended for pre-bachelor and pre-master students of technical universities. It is aimed to develop skills of reading and comprehension of scientific articles, textbooks and manuals on various technical specialties, skills of comprehending listening to lectures, and skills of writing one's own texts (abstracts, term papers, theses, reports). There is no doubt that these skills are essential for students in their learning activities. The university curriculum includes a limited amount of Russian class hours, and the new online course could be a great help for BMSTU foreign students.

\section{Conclusion}

What is a modern teacher in the digital age? It is a specialist who is qualified not only in his/her subject, but also in digital technologies, and is able to create presentations, online courses, computer tests.

We live in an exciting era of new opportunities, experiments, creativity and new ways of application of pedagogical talents. We have to assume that, we can't avoid difficulties, trial and error, significant investment of time and energy. But we believe that we are on the right way. We can say that the experiment allowed us to step into the future and see the new "teacher-student" interaction, in which the student's individual work online comes to the fore, and the live lessons with the teacher become more precious (when students get a chance to ask questions on the studied material). The student's activity and productivity grow both in self-study and in the classroom. The experiment showed that the new teaching methodology significantly optimizes the learning process and increases students' motivation. It won't be long before the innovative method described in this article becomes common.

\section{References}

1. N.N. Romanova and T.P. Skorikova, Linguistic and Methodological Fundamentals of Developing the Scientific Speech Course for Postgraduate Students of a Technical University, Mod. J. of Lang. Teach. Meth., Vol. 8, No. 11, pp. 1006-17 (2018)

2. G.V. Kirsanova and V.A. Lazarev, Content and Language Integrated Learning: A New Approach to Teaching Engineering, Handbook of Research on Engineering Education in a Global Context, Vol. 2, ed IGI Global Chapter 25 in E.V. Smirnova and Robin P., Clark. chapter 25, pp. 1-541 (2018)

3. T.P. Skorikova, S.S. Khromov and N.V. Dneprovskaya, Distance Learning in Scentific and Professional Fields of Communication (Interdisciplinary Approach), Intern. J. of Envir. \& Sc. Educ., vol. 11, no. 10, pp. 3467-76 (2016) 
4. E.G. Azimov, Massive open online courses: problems of creation and use in teaching Russian as a foreign language Problems of teaching philological disciplines to foreign students, Materials IV Int. Scientific Method Voronezh, CPI "Scientific Book", pp. 10-13 (2016)

5. E.G. Azimov, Massive open online courses: problems of creation and use in teaching Russian as a foreign language Problems of teaching philological disciplines to for [5] Karpov A.O. 2015 Formation of the Modern Concept of Research Education: from New Age to a Knowledge Society Worldwide Trends in the Development of Education and Academic Research, Procedia Social and Behavioural Sciences, vol. 214, pp. 439447 (2016)

6. A.O. Karpov, University 3.0, Social Mission and Realty Sotsiologicheskie Issledovaniya, no. 9, pp. 114-124 (2017)

7. D. Lederman, Growth for Online Learning InsideHigherEd (2013). https://www.insidehighered.com/news/2013/01/08/survey-finds-online-enrollmentsslow-continue-grow\#.UTpqK6RUk3B.delicious, last accessed 2016/10/16.

8. L. Armstrong, Distance learning: An academic leader's perspective on a disruptive product Change, 32(6), pp. 20-27 (2000)

9. N.Sh. Kozlova, Digital technologies in education, Bulletin of Maykop State Technological University, no. 1/40, pp. 85-93 (2019)

10. T.E. Lebedeva, N.V. Okhotnikova and E.A. Potapova, Electronic educational environment of the university: requirements, opportunities, experience and prospects of use, World of Science, vol. 4, no. 2, pp. 1-12 (2016)

11. Y.I. Dimitrienko, E.A. Gubareva and M.P. Gordin, A new methodology for teaching the course "Mathematical Analysis" in the digital environment "NOMOTEX" for engineers Innovative Development, no. 8 (25), pp. 8-11 (2018)

12. Sputnik (Satellite), Russian as a foreign language. Elementary level: study guide 2019, Moscow, BMSTU Publ., p. 476 (2019)

13. E.V. Pinevich, G.M. Petrova, E.A. Orlov, N.N. Romanova, Testing Problems in Russian as a Foreign Language in a Technical University, Journ. of Research in Appl.Ling., vol. 10, pp. 137-157 (2019)

14. E.V. Pinevich, On the structure of the online course on Russian as a foreign language. II World Congress in real and virtual space "East-West: intersection of cultures", Kyoto: Tanaka Print, vol. 1, pp. 541-546 (2019)

15. O.I. Meshcheryakova, MOOCs technologies and their use in the organization of blended learning, Remote and virtual learning, no. 3, pp. 18-29 (2016)

16. N.A. Ionova, The role of the online course in teaching Russian to foreign students of the entry-level preparatory department. International Forum "Digital Technologies in Engineering Education: New Trends and Implementation Experience", Moscow, BMSTU Publ., pp. 45-48 (2019)

17. O.E. Solyanik, Creation of an online Russian language course for foreign students of the preparatory faculty of a technical university International forum "Digital technologies in engineering education: new trends and implementation experience", Moscow, BMSTU Publ., pp. 95-97 (2019)

18. K.G. Krechetnikov, Features of the organization of blended learning, Modern problems of science and education, no. 4 (2019). URL: http://scienceeducation.ru/ru/article/view?id=29019, last accessed 2019/12/19. 
19. E.A. Stracke, Road to understanding: A qualitative study into why learners drop out of a blended language learning (BLL) environment ReCALL, no. 19 (1), pp. 57-78 (2010)

20. I.I. Prosvirkina, T.A. Sadretdinova, M.D. Yakhno and A.M. Frolova, The use of blended learning models in teaching speaking: Philological sciences. Questions of theory and practice, Tambov: Diploma, no. 12 (78), P. 4, pp. 202-205 (2017) 